\title{
Impacto da combinação de inseticidas sobre a produção de repolho e parasitóides associados com a traça-das-crucíferas.
}

\author{
Félix Humberto França; Maria Alice de Medeiros \\ Embrapa Hortaliças, Laboratório de Entomologia, C. Postal 218, 70.359-970 - Brasília DF.
}

\section{RESUMO}

A produção comercial de repolho foi obtida de parcelas que receberam combinações de doses de deltametrina $25 \mathrm{CE}$ e abamectin $18 \mathrm{CE}$ as quais proporcionaram controle dos danos causados pela traça-das-crucíferas, Plutella xylostella (L.) (Lepidoptera: Yponomeutidae). Os resultados foram comparáveis àqueles obtidos pela pulverização de formulação concentrada emulsionada de Bacillus thuringiensis. A utilização isolada de deltametrina $25 \mathrm{CE}$ e abamectin $18 \mathrm{CE}(0,51 / \mathrm{ha})$ resultou em baixos níveis de produção comercial, respectivamente 7 e $8 \%$. As misturas deltametrina e abamectin produziram mais de $42 \%$. A elevada densidade populacional da praga fez com que não fosse obtida produção comercial na área não tratada. Os inseticidas ou suas combinações testadas não provocaram qualquer impacto, estatisticamente mensurável, sobre populações das espécies dos parasitóides Diadegma spp. (Hymenoptera: Ichneumonidae) e Apanteles spp. (Hymenoptera: Braconidae).

Palavras-chave: Plutella xylostella, Brassica oleracea var: Capitata; Diadegma spp., Apanteles spp., repolho, seletividade, controle químico, eficiência agronômica.

\begin{abstract}
Efficiency on cabbage production and impact of insecticide mixtures on parasitoids of diamondback moth.

Commercial cabbage heads were obtained from plots sprayed with mixtures of deltamethrin $25 \mathrm{CE}$ and abamectin $18 \mathrm{CE}$, which provided control of the damages caused by the Diamondback moth, Plutella xylostella (L.) (Lepidoptera: Yponomeutidae). Results were similar to those obtained from plots sprayed with the liquid formulation of the biological insecticide Bacillus thuringiensis. Deltamethrin and abamectin produced less than $8 \%$ of commercial cabbage, whereas the mixture abamectin + deltamethrin produced more than $42 \%$. There was no commercial production in the untreated plots due to the high population densities of the pest. Insecticides alone or combinations did not cause any measurable impact on the populations of natural enemies Diadegma spp. (Hymenoptera: Ichneumonidae) or Apanteles spp. (Hymenoptera: Braconidae).
\end{abstract}

Keywords: Plutella xylostella, Brassica oleracea var. capitata, Diadegma spp., Apanteles spp., cabbage, selectivity, chemical control, field test efficiency.

\section{(Aceito para publicação em 03 de junho de 1998)}

\section{A traça-das-crucíferas (TDC), A Plutella xylostella (Linnaeus)} (Lepidoptera: Yponomeutidae) é a principal praga do repolho, couve-flor, brócoli, mostarda e canola, no Brasil e em muitos países nos cinco continentes. Entre as táticas empregadas no seu controle, o uso de inseticidas é o mais adotado entre os produtores de brássicas em geral. A história do desenvolvimento de produtos para o controle de TDC mostra que em determinado momento, inseticidas de todos os grupos químicos, foram eficientes no controle da praga (França et al., 1985; Barros et al., 1993; Silva et al., 1993; Talekar \& Shelton 1993; Castelo Branco et al., 1996). Contudo, o inseto possui variabilidade genética que permite adaptação aos inseticidas independente do aumento da dose utilizada ou freqüência de aplicações, que, favorecem o surgimento de populações resistentes, que rapidamente se multiplicam e dispersam
(Tabashnik et al., 1987). Com isso há necessidade de contínua busca de novos inseticidas, formulações, doses e combinações de produtos que possibilitem seu controle de modo eficiente.

O objetivo deste trabalho foi definir produtos ou combinações de produtos e doses que proporcionem o controle eficiente da TDC, bem como, avaliar o impacto destes em um complexo de parasitóides associados à larvas e pupas do inseto. estas informações são demandadas freqüentemente por produtores de hortaliças de diversas regiões brasileiras e são importantes na medida que podem significar o aumento da margem de lucro do produtor que terá oportunidade de oferecer um produto de melhor qualidade estética num mercado competitivo. o conhecimento da seletividade dos inseticidas sobre inimigos naturais permite a melhor escolha visando o uso racional desses produtos, contribuindo para a reduzir o impacto destes sobre o meio ambiente.

\section{MATERIAL E MÉTODOS}

O experimento foi conduzido no campo experimental da Embrapa Hortaliças, Brasília, DF, em uma área de latossolo vermelho escuro. A cultivar utilizada foi o repolho Kenzan, que é o preferido pelos produtores do DF e Goiás. A semeadura ocorreu em 30 de maio, e as mudas foram transplantadas em 26 de junho.

As coletas de dados foram realizadas entre 13 de agosto e 11 de setembro, período do ano que corresponde, geralmente, às mais altas infestações do inseto na região devido à ausência de precipitação pluviométrica $(<5 \mathrm{~mm} /$ mês), baixa umidade relativa $(20 \%$ $50 \%)$ e temperaturas médias das máximas elevadas $\left(26^{\circ} \mathrm{C}-30^{\circ} \mathrm{C}\right)$. A adubação utilizada foi de aproximadamente $500 \mathrm{~g}$ da formula 4-30-16 e 500g de esterco de galinha por cova, sendo a área irrigada duas vezes por semana através 
Tabela 1. Inseticidas utilizados no ensaio de controle da traça-das-crucíferas Plutella xylostella em repolho e impacto em duas espécies de parasitóides. Brasília - DF, Embrapa Hortaliças, 1997.

\begin{tabular}{|c|c|c|c|c|c|c|}
\hline $\begin{array}{c}\text { Nome } \\
\text { comercial }\end{array}$ & Nome Técnico & Nome químico & Concentração & Formulação & $\begin{array}{c}\text { Grupo } \\
\text { químico }\end{array}$ & Classe \\
\hline Abamectin & Abamectin & $\begin{array}{l}5 \text { 0-demetilavermectin } \\
\text { A1a }+(50 \text {-demetil }) 25 \\
\text { de (1-metil propil) } 25(1 \\
\text { metiletil) Avermectin A1a }\end{array}$ & 18 g.i.a./11/ & $\begin{array}{l}\text { Concentrado } \\
\text { emulsionável }\end{array}$ & & $\begin{array}{l}\text { Acaricida } \\
\text { inseticida de } \\
\text { origem biológica }\end{array}$ \\
\hline $\begin{array}{l}\text { B. thuringiensis } \\
8 \mathrm{E}\end{array}$ & $\begin{array}{l}\text { Bacillus } \\
\text { thuringiensis } \\
\text { var. kurstaki }\end{array}$ & $\begin{array}{l}\text { Bacillus thuringiensis } \\
\text { var. kurstaki }\end{array}$ & $\begin{array}{l}36.000 \text { U.I. 2/ } \\
\text { B. } \\
\text { thuringiensis/mg }\end{array}$ & $\begin{array}{l}\text { Suspensão em } \\
\text { óleo }\end{array}$ & Biológico & $\begin{array}{l}\text { Inseticida } \\
\text { biológico }\end{array}$ \\
\hline Deltametrina & Deltametrina & $\begin{array}{l}\text { (S)- alfa-ciano-m- } \\
\text { fenoxibenzil-2,2dimetil-ci- } \\
\text { clopropano-carboxilato }\end{array}$ & 25 g.i.a./11/ & $\begin{array}{l}\text { Concentrado } \\
\text { emulsionável }\end{array}$ & Piretróide & Inseticida \\
\hline
\end{tabular}

${ }^{1 /}$ Gramas de ingrediente ativo por litro.

de um sistema de irrigação por aspersão convencional que aplicava o equivalente a $10 \mathrm{~mm}$ de lâmina bruta de água/dia, no decorrer do ensaio.

O delineamento experimental foi em blocos ao acaso com quatro repetições e cada parcela apresentou 48 plantas dispostas em três fileiras, no espaçamento de $1,0 \mathrm{~m} \times 0,5 \mathrm{~m}$. Foram utilizadas as formulações em concentrado emulsionável dos seguintes produtos ou combinações de produtos nas seguintes doses, que corresponderam aos tratamentos: (1) deltametrina $25 \mathrm{CE} 0,301 / \mathrm{ha}+$ abamectin

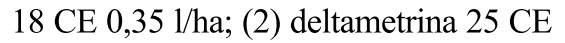
$0,30 \mathrm{l} / \mathrm{ha}+$ abamectin $18 \mathrm{CE} 0,25 \mathrm{l} / \mathrm{ha}$; (3) deltametrina $25 \mathrm{CE} 0,201 / \mathrm{ha}+$ abamectin $18 \mathrm{CE} \quad 0,25 \mathrm{l} / \mathrm{ha}$; (4) deltametrina $25 \mathrm{CE} 0,151 /$ ha + abamectin 18 CE 0,25 1/ha; (5) deltametrina CE 0,30

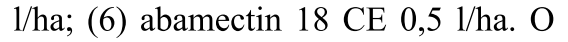
produto comercial na formulação emulsionável, Bacillus thuringiensis, suspensão em óleo na dose de 0,50 1/ha foi utilizado como inseticida padrão (Tabela 1). Uma parcela pulverizada apenas com água e espalhante adesivo foi considerada como testemunha. Os volumes de calda utilizados variaram entre $2.600 \mathrm{ml} \mathrm{e} 4.000 \mathrm{ml} /$ tratamento, equivalentes a aproximadamente a 394 litros - 615 litros de calda/ha, entre a primeira data de pulverização (17/7/97) e a última (21/08/97). Todas as pulverizações incluíram o espalhante adesivo, um óleo mineral a $0,25 \%$ e foram realizadas com pulverizador costal manual, com capacidade para 18 litros de solução. As pulverizações foram iniciadas quando as plantas apresentavam-se no início da formação das cabeças e reali- zadas até 14 dias antes da colheita do repolho. As três primeiras pulverizações foram realizadas em intervalos de 14 dias e as duas últimas em intervalos semanais, totalizando cinco pulverizações no período. O que determinou o início e o intervalo das pulverizações foi a presença de adultos do inseto voando quando as plantas eram perturbadas e se as folhas em torno da cabeça do repolho em formação apresentavam aproximadamente 6 furos causados por larvas de terceiro e quarto ínstares em cada planta.

Considerando-se o hábito de alimentação das larvas de TDC, geralmente individualizadas em cada sítio de alimentação, correspondendo cada furo à presença de uma larva, e a densidade de plantas por unidade de área, os tratamentos foram iniciados ou continuados quando a densidade da praga atingiu aproximadamente 12 larvas $/ \mathrm{m}^{2}$. Em geral foram amostradas 30 plantas escolhidas ao acaso em quatro repetições (Castelo Branco et al., 1996; 1997).

A eficiência dos tratamentos foi avaliada por ocasião da colheita, determinando-se o número de furos presentes em quatro folhas da saia externa e na cabeça de repolho de tamanho comercial. Os danos foram classificados nas seguintes notas: $1=$ folhas da saia externa e cabeça de repolho com poucos furos pequenos; 2 = idem, com furos pequenos e médios; 3 =idem, com furos médios, 4 = idem, com furos grandes, 5 = cabeça de repolho destruída, imprópria para comercialização, ou planta com cabeça não formada devido aos danos da TDC. Os dados foram submetidos à análise de variância e as mé- dias foram comparadas pelo teste da Diferença Mínima Significativa (Fischer's Protected LSD). A porcentagem de cabeças de repolho com aceitação comercial, por tratamento, foi definida em função do número total de plantas nas quatro parcelas, e se refere a cabeças bem formadas, pesando aproximadamente 1.200-1.400 gramas, com nenhum ou poucos furos pequenos.

A avaliação do impacto dos inseticidas e suas combinações sobre parasitóides foi efetuada determinandose o número de adultos de Diadegma spp. (Hymenoptera: Ichneumonidae) e Apanteles spp. (Hymenoptera: Braconidae), que apresentavam comportamento de busca sobre três plantas em cada parcela em três datas durante o experimento. Os dados foram transformados para $\log (\mathrm{x}+1)$, submetidos à análise de variância e, as médias separadas pelo mesmo teste.

\section{RESULTADOS E DISCUSSÃO}

$\mathrm{O}$ número de furos associados às notas de dano evidenciam a elevada população da praga durante a realização do experimento (Tabelas 2 e 3). Em razão da alta população de TDC, as cabeças de repolho de nota igual ou superior a 2,0 não foram consideradas comercializáveis, devido ao grande número de furos médios e grandes, além da presença de larvas e pupas do inseto (Tabela 2). A combinação dos inseticidas deltametrina $25 \mathrm{CE} 0,20 \mathrm{l} / \mathrm{ha}$ e abamectin $18 \mathrm{CE} 0,25 \mathrm{l} / \mathrm{ha}$ possibilitou a obtenção da maior quantidade de cabeças comerciais de repolho (85\%) sen- 
Tabela 2. Número de furos causados por larvas de Plutella xylostella em quatro folhas da saia externa e cabeça de tamanho comercial de repolho. Brasília - DF, Embrapa Hortaliças, 1997.

\begin{tabular}{cc}
\hline Nota de dano ${ }^{\mathbf{1}}$ & $\begin{array}{c}\mathbf{N}^{\mathbf{0}} \text { de furos } \\
\left(\mathbf{M e ́}^{\text {dia }} \pm \mathbf{E P M}^{\mathbf{2}} / \mathbf{)}\right.\end{array}$ \\
\hline 1 & $17,0 \pm 3,2$ \\
2 & $38,8 \pm 6,5$ \\
3 & $114,5 \pm 4,6$ \\
4 & $181,0 \pm 4,2$ \\
5 & $280,6 \pm 10,0$ \\
\hline
\end{tabular}

${ }^{1 /}$ Nota de dano se refere a furos nas quatro folhas da saia externa e em cabeça de repolho: $(1)=$ folhas da saia externa e cabeça de repolho com poucos furos pequenos; $(2)=$ idem a (1), com furos pequenos e médios; (3) = idem a (1 e 2), com furos médios, (4) =idem a $(1,2$ e 3$)$, com furos grandes, (5)= cabeça de repolho destruída; imprópria para comercialização, ou planta com cabeça não formada devido aos danos da TDC.

${ }^{2}$ Média do número de furos e erro padrão da média.

do aproximadamente $19 \%$ superior ao padrão $B$. thuringiensis $8 \mathrm{E} \quad 0,501 /$ ha (Tabela 3).

Entre os tratamentos, apenas deltametrina $25 \mathrm{CE}$ aplicado na dose de 0,30 litro por hectare não diferiu da testemunha, no que se refere a nota de dano produzindo apenas $7 \%$ de cabeças de repolho comercializáveis (Tabela 3). Este resultado já era esperado, porque este produto vem sendo aplicado há quase duas décadas no Distrito Federal e, eventualmente, apresenta episódios de falha de controle que pode ser atribuída a dois fatores: (a) aumento da frequência dos genes que conferem resistência ao produto (Castelo Branco \& Gatehouse, 1997); (b) alta temperatura que ocasionalmente pode influenciar negativamente a eficiência relativa de inseticidas piretróides.

A aplicação de abamectin isoladamente produziu apenas $8 \%$ de cabeças comerciais, tendo sido atribuída a nota de dano de 2,3 $\pm 0,6$ ao tratamento (Tabela 3 ). Nos ensaios conduzidos sob infestação moderada da praga, França et al. (1985) e Castelo Branco \& Guimarães (1990) verificaram que abamectin, aplicado nas doses de $20 \mathrm{~g}$ i.a./ha (mais de 1 litro/PC/ha) e 11,5 g i.a./ha (aproximadamente $640 \mathrm{ml} / \mathrm{PC} /$ ha), foi eficiente no controle da TDC. A baixa produção comercial obtida com o tratamento abamectin não pode ser explicada pela resistência da população ao produto. Em junho de 1996, a susceptibilidade da população de TDC da Embrapa Hortaliças a abamectin foi avaliada utilizando-se larvas de terceiro ínstar $(\mathrm{n}=361)$. Foi determinada uma $\mathrm{LC}_{50}=0,19(0,003-2,86) \mathrm{ml} /$ ha equivalente a 2.100 vezes menor que a dose recomendada para eliminar $50 \%$ da população (Castelo Branco, dados não publicados), o que demonstra a susceptibilidade da mesma ao inseticida. Estes resultados concordam com Castelo Branco (1997), que sugere que outros fatores além daqueles que condicionam a resistência a inseticidas devem estar envolvidos, como por exemplo, a densidade populacional do inseto na época de condução dos experimentos.

Todas as misturas de deltametrina e abamectin não diferiram do tratamento padrão $B$. thuringiensis $8 \mathrm{E}$ de acordo com o critério de avaliação utilizado (Tabela 3). B. thuringiensis é utilizado no DF e estado de Goiás desde 1977 onde tem mostrado alta eficiência relativa (Barbosa \& França 1980; Barros et al., 1993), muito embora haja evidências de que a resistência à toxina de $B$. thuringiensis exista na região (Campos et al., 1997).

Ainda que se considere que a população da TDC no DF apresente resistência ao piretróide (Castelo Branco \& Gatehouse, 1997), a eficiência da mistura entre os produtos deltametrina e abamectin, independente das doses utilizadas no controle do inseto, pode ser explicada pelo fato de que apesar dos insetos sobreviverem à um dos produtos, deltametrina, eventualmente sucumbem ao outro, abamectin.

A melhor eficiência relativa das misturas em comparação com abamectin isolado pode ser explicada pela hipótese de que a presença do piretróide deltametrina contribui para aumentar a persistência de abamectin. Souza (1997) demonstrou que a qualidade da luz solar, mas não a precipitação ou intensidade da irrigação por aspersão, pode afetar a persistência de abamectin. Castelo Branco (1997) mostrou que a com-

Tabela 3. Seletividade e impacto do uso de inseticidas e combinações no dano causado por larvas de Plutella xylostella nas folhas da saia externa e cabeça de tamanho comercial de repolho. Brasília - DF, Embrapa Hortaliças, 1997.

\begin{tabular}{|c|c|c|c|}
\hline Tratamentos (dose $\mathbf{l} / \mathbf{h a})$ & $\begin{array}{c}\text { Parasitóides }^{1} \\
\text { Média } \pm \text { EPM }\end{array}$ & $\begin{array}{l}\text { Nota de dano }{ }^{2} \\
\text { Média } \pm \text { EPM }\end{array}$ & $\begin{array}{l}\text { \% Cabeças } \\
\text { Comerciais }^{3}\end{array}$ \\
\hline Deltametrina $25 \mathrm{CE}(0,20)+$ Abamectin $18 \mathrm{CE}(0,25)$ & $11,6 \pm 3,7 \mathrm{a}$ & $1,4 \pm 0,1 \mathrm{a}$ & 85 \\
\hline B. thuringiensis $8 \mathrm{E}(0,50)$. & $22,0 \pm 8,9 \mathrm{a}$ & $1,6 \pm 0,1 \mathrm{a}$ & 66 \\
\hline Deltametrina $25 \mathrm{CE}(0,30)+$ Abamectin $18 \mathrm{CE} 0,35$ & $12,2 \pm 3,6 \mathrm{a}$ & $1,6 \pm 0,2 \mathrm{a}$ & 60 \\
\hline Deltametrina $25 \mathrm{CE}(0,30)+$ Abamectin $18 \mathrm{CE}(0,25)$ & $12,8 \pm 4,9 \mathrm{a}$ & $2,0 \pm 0,5 \mathrm{a}$ & 56 \\
\hline Deltametrina $25 \mathrm{CE}(0,15)+$ Abamectin $18 \mathrm{CE}(0,25)$ & $15,3 \pm 5,0 \mathrm{a}$ & $2,1 \pm 0,6 \mathrm{a}$ & 42 \\
\hline Abamectin $18 \mathrm{CE}(0,50)$ & $13,4 \pm 2,8 \mathrm{a}$ & $2,3 \pm 0,6 \mathrm{a}$ & 8 \\
\hline Deltametrina $25 \mathrm{CE}(0,30)$ & $13,6 \pm 3,3 \mathrm{a}$ & $3,9 \pm 0,2 b$ & 7 \\
\hline Testemunha & $18,3 \pm 4,2 \mathrm{a}$ & $4,8 \pm 0,3 b$ & 0 \\
\hline
\end{tabular}

${ }^{1}$ Média e erro padrão da média, em três datas de contagens do número de adultos de .

${ }^{2}$ Média do número de furos e erro padrão da média seguidas da mesma letra não diferem entre si.

${ }^{3}$ A porcentagem determinada em função do número total de plantas se refere a cabeças bem formadas. 
binação de $B$. thuringiensis e abamectin foi eficiente para o controle de TDC, sendo provável que além das características do inseticida, o fato da formulação de $B$. thuringiensis conter óleo, influencie a persistência do abamectin. Em tomate, a adição de óleo mineral na calda inseticida, abamectin aumentou sua persistência e eficiência relativa no controle da traça-do-tomateiro (Castelo Branco \& França, 1996).

O repolho híbrido Kenzan em condições ótimas de produção, com plantio em fevereiro-março e colheita em maiojunho, quando há ocorrência de precipitação e temperaturas médias relativamente baixas, pouca incidência de insetos (pulgão e TDC) e doenças, chega a produzir entre $90 \%$ e $95 \%$ de cabeças comerciais, sendo esta perda atribuída a fatores agronômicos. Considerando a época de realização do experimento e a alta infestação da TDC, a produção comercial alcançada pelos tratamentos com nota de dano igual ou inferior a 2,0 foi superior a $50 \%$ da produção (Tabelas 2 e 3). Nas condições de produção no Distrito Federal, entre agosto e novembro, é muito comum produtores de brássicas abandonarem o cultivo devido às dificuldades de comercialização da produção por causa da depreciação causada pelos danos da TDC. Nestes casos, em geral localizados em áreas de produção específicas, inseticidas fosforados e piretróides foram utilizados e resistência a estes produtos foi constatada (Castelo Branco, 1997).

O número de adultos de parasitóides de larvas e pupas de TDC, Diadegma spp. e Apanteles spp. observado nas parcelas pulverizadas com o inseticida biológico $B$. thuringiensis e nas parcelas que não receberam pulverização com calda inseticida foi maior que aquele registrado para as combinações de in- seticidas, não havendo, entretanto, diferença estatística significativa entre qualquer dos tratamentos (Tabela 3). Em todos os tratamentos foi observada uma população de parasitóides muito alta (média $>4,0$ adultos/planta). Contudo, este fato pode ser explicado porque adultos de parasitóides escapam do contato direto das pulverizações e, portanto, há constante renovação e suprimento destas populações na área.

\section{AGRADECIMENTOS}

Os autores agradecem a Vilmondes Geraldo Borges, Paulo Leonardo de Lima, Hozanan Pires Chaves e Ronildo Cosmo Gonçalves pelo auxílio na condução dos trabalhos de campo e laboratório; a Marina Castelo Branco pela revisão e sugestões apresentadas ao texto e à Hoechst Schering Agrevo do Brasil Ltda. pelo apoio financeiro.

\section{LITERATURA CITADA}

BARBOSA, S.; FRANÇA, F.H. Controle de Plutella xyllostella (L.) em repolho através de inseticidas organossintéticos e Bacillus thuringiensis. In. CONGRESSO BRASILEIRO DE ENTOMOLOGIA, 6., 1980, Campinas, SP. Resumos... Campinas: SOB, 1980. p. 105.

BARROS, R.; ALBERT JUNIOR, I.B.; OLIVEIRA, A.J. de; SOUZA, A.C.F. de; LOPES, V. Controle químico da traça-das crucíferas, Plutella xylostella (L.) (Lepidoptera: Plutellidae) em repolho. Anais da Sociedade Entomologica do Brasil, Jaboticabal, v. 22, n. 3, p. 463 - 469, 1993.

CAMPOS, L.C.A.; CASTELO BRANCO, M.; JUNQUEIRA, A.M.R. Susceptibilidade de três populações de traça-das-crucíferas a Bacillus thuringiensis. Horticultura Brasileira, Brasília, v. 14, n. 1, p. 36 - 38, 1997.

CASTELO BRANCO, M.; GUIMARÃES, A.L. Controle da traça-das-crucíferas em repolho, 1989. Horticultura Brasileira, Brasilia, v. 8 , n. 1 , p. $24-25,1990$.
CASTELO BRANCO, M.; FRANÇA, F.H. Eficiência relativa de inseticidas em mistura com óleo mineral sobre o nível de dano econômico da traça-do-tomateiro. Horticultura Brasileira, Brasília, v. 14, n. 1, p. 36 - 38, 1996.

CASTELO BRANCO, M.; VILLAS BÔAS, G.L.; FRANÇA, F.H. Nível de dano de traça-dascrucíferas em repolho. Horticultura Brasileira, Brasília, v. 14, n. 2, p. 154 - 157, 1996.

CASTELO BRANCO, M. Inseticide resistance in Plutella xylostella (Linnaeus) (Yponomeutidae) in the Federal District, Brazil; effects of local and long-range movement of moths. Bangor: University of Wales, 1997. 196 p. (Tese doutorado).

CASTELO BRANCO, M.; GATEHOUSE, A.G. Insecticide resistance in Plutella xylostella (L.) (Lepidoptera: Yponomeutidae) in the Federal District, Brazil. Anais da Sociedade Entomologica do Brasil, Jaboticabal, v. 26, p. $75-79,1997$.

CASTELO BRANCO, M.; FRANÇA, F.H.; VILLAS BÔAS, G.L. Traça-das-cruciferas Plutella xylostella. (Brasília: EMBRAPACNPH, 1997. 4 p. (EMBRAPA-CNPH. Comunicado Técnico da Embrapa Hortaliças, 4).

FRANÇA, F.H.; CORDEIRO, C.M.T.; GIORDANO, L. DE B.; RESENDE, A.M. Controle da traça das crucíferas em repolho, 1984. Horticultura Brasileira, Brasília, v. 3, n. 2, p. 50 - 51, 1985.

SILVA, A.L. da; VELOSO, V.R.S.; TARDIVO, J.C.; ABREU, C.D. de; SILVA, R.M. de C. e. Avaliação de inseticidas piretróides no controle da traça-das crucíferas, Plutella xylostella (L., 1758) em repolho. Anais das Escolas de Agronomia e Veterinaria, Goiânia, v. 23, n. 1, p. 7 - 12, jan./dez, 1993.

SOUZA, E. dos S. Persistência de inseticidas em plantas de repolho. Brasília: UnB, 1997. 23 p. (Relatório final de estágio).

TABASHNIK, B.E.; CUSHING, N.L.; JOHNSON, M.W. Diamondback moth (Lepidoptera: Plutellidae) resistance to insecticides in Hawaii: Inter-Island variation and cross resistance. Journal of Economic Entomology, v. 80, p. 1091 - 1099, 1987.

TALEKAR, N.S.; SHELTON, A.M. Biology, ecology and management of the diamondback moth. Annual Review of Entomology, v. 38, p. 275 - 301, 1993. 